www.jmscr.igmpublication.org

Index Copernicus Value: 79.54

ISSN (e)-2347-176x ISSN (p) 2455-0450

crossref DOI: https://dx.doi.org/10.18535/jmscr/v7i3.221

\title{
Comparative Study of Fracture Metacarpals Treated by Orif by Minifragment Plate vs Closed Kirschner's Wire Fixation
}

\author{
Authors \\ Maninder Singh ${ }^{1}$, Partap Singh Verka ${ }^{2 *}$, Himanshu Agrahari, Tapish Sukla ${ }^{4}$ \\ Mohit Singla ${ }^{5}$, Nishit Singh ${ }^{6}$, Kashish Talwar ${ }^{7}$ \\ ${ }^{1}$ Assistant Professor, Department of Orthopaedics, Govt. Medical College, Amritsar, India \\ ${ }^{2}$ Professor and Head, Department of Orthopaedics, Govt. Medical College, Amritsar, India \\ 3,4,5,7 Junior Resident, Department of Orthopaedics, Govt. Medical College, Amritsar, India \\ ${ }^{6}$ Senior Resident, Department of Orthopaedics, ESI Hospital, Rohini, Delhi \\ *Corresponding Author
}

Dr Partap Singh Verka

Email: singhdr.partap@yahoo.in

\begin{abstract}
Background: There is an increasing tendency to use Minifragment plates over Kirschner's wire for treating hand fractures. The superior method of internal fixation by minifragment plate has several advantages over the Kirschner's wire. The purpose of this comparative study was to evaluate the differences between these two techniques of internal fixation in fractures of metacarpals in terms of radiological union and functional outcome.

Patients and Methods: The study included a total of 30 patients with a mean age of 35.6 years. The patients were divided into two groups (Group A - treated with minifragment plate and Group B - treated with Kirschner's wire) with 15 cases each at Government Medical College and Hospital, Amritsar. The outcomes of treatment were compared in the two groups using Student's t-test and chi-square test.

Results: The average time for radiological union in Group A (minifragment plate) was 7.2 weeks, while it was 9 weeks in Group B (Kirschner's wire). There was no statistically significant difference in the radiological union time between the two groups $(P=0.274$, chi-square $=2.59)$. Stiffness was the most common associated complication in this study. It was more common in the group treated with Kirschner's wire $(26.7 \%)$ compared to the group treated with Minifragment plating (13.3\%). In Group A, $86.7 \%$ of cases had shown good to excellent results; while in Group B, 80\% of the cases had similar result. There was no statistically significant difference $(P=0.938$, chi-square $=0.410)$ in outcome in both groups.

Conclusions: Both Kirschner's wire and minifragment plate are good methods of internal fixation in fractures of metacarpal. Though patients who were treated with minifragment plating had better functional results, but the difference was not statistically significant.

Keywords: Kirschner's wire, minifragment plate, metacarpal fracture.
\end{abstract}

\section{Introduction}

The main function of the hands include both fine and gross motor skills as well as a key tool for sensing and understanding the immediate surroundings. Swanson aptly stated "Hand fractures can be complicated by deformity from 
no treatment, stiffness from overtreatment, and both deformity and stiffness from poor treatment". ${ }^{1}$ Hand fractures are the most common fractures presenting at emergency and within orthopaedic clinics. Fractures of metacarpals and phalanges constitute between $14-28 \%$ of all visits to the emergency department. ${ }^{2}$ Non-thumb metacarpals account for around $88 \%$ of all metacarpal fractures, with the fifth finger most commonly involved. ${ }^{3}$ Fracture healing in the hand is not an isolated goal rather the functional result is of paramount importance. ${ }^{4}$ Recent studies have shown good functional results with surgical treatment of metacarpal fractures using miniplates and screws as compared to the conservative treatment or $\mathrm{K}$-wire fixation. This study involves evaluating functional outcome of metacarpal fractures treated with miniplates and $\mathrm{K}$-wire fixation. ${ }^{5}$

\section{Patients and Methods}

The study consisted of a total of 30 cases. A case of either sex > 15 years old with fracture of metacarpal admitted in the department of orthopaedics at Government Medical College, Amritsar were randomly selected for the study. The study was undertaken after approval of Institutional Ethics Committee, Government Medical College, Amritsar. Written informed consent of the patient was obtained before inclusion in the study. The 30 selected cases were divided into two equal groups (group A and group B) of 15 cases each. The cases of group A were treated with Minifragment plate in metacarpal. The cases of the group B were treated with kirschner's wire in metacarpal. Clinical history, general physical examination and local examination was performed as per proforma attached the classification of fracture was made as per OTA classification. Patient was investigated for operative and anaesthetic purposes. As the hand injury may be associated with multiple injuries, so the cases were assessed clinically, resuscitated (if required) and treated accordingly. The supportive and prophylactic therapy in the form of analgesics, antibiotics, anti tetanus injection, I.V. fluids, matched blood transfusion, wherever required, were given to stabilize the vitals. All operative procedures were done under appropriate anaesthesia and under tourniquet control.

\section{Operative Procedures for Inserting Kirschner's Wire}

The fracture site was painted and draped and after the closed reduction of the fracture endsk-wire was inserted under $\mathrm{x}$ ray control.

\section{Operative Procedure For Minifragment Plating in Metacarpal}

The fracture site was exposed through dorsal longitudinal incision. Fracture site was exposed after retracting the extensor tendon and reduction was held by an assistant and the appropriate plate was applied over fracture site and was fixed with the help of appropriate screw size. The Minifragment plate was centered with the middle hole over the fracture site and secured without compression by insertion of mini screws into the centre of the holes on either end of the Minifragment plate. In all the above procedures, the wound was stitched in layers, tourniquet was released and antiseptic dressing was done over the wound.

\section{Postoperative Management}

The operated limb was kept elevated for 48 hours. Broad spectrum I/V antibiotics, anti-inflammatory and analgesics was given. Radiological examination was done on next day of the operation to confirm the fixation of reduction. The first postoperative dressing was done on the fifth day. Active range of motion exercises was commenced on the 1st postoperative day.

Alternate stitches was removed on 10th and all remaining on 12 th post operative day.

\section{Follow-up}

The patients were examined every three weekly till union. On every visit patient was examined 
clinically and X-rays of the hand showing fracture site was taken. Radiological sign of union, displacement if any, implant failure or any angulation was recorded. Clinically patients were examined for any tenderness, infection or pain and was treated accordingly. Movements of distal interphalangeal, proximal interphalangeal and metacarpophalangeal joints was recorded. During the period of follow up, only active exercises at physiotherapy centre or at home was advocated.

\section{Evaluation of Result}

The functional outcome after fracture treatment was assessed by calculating total active range of motion (TAM) as suggested by American Society for the Surgery of Hand (ASSH). This was done by adding active flexion at metacarpophalangeal, proximal interphalangeal and distal interphalangeal joints, after subtracting the sum of extension deficit at these joints. Recovery was calculated as percent-regained motion compared to normal range of motion (270 degrees). Results was evaluated according to Strickland's original classification. Patients with $85-100 \%$ of TAM was described as excellent; $70-84 \%$ as good; 50 $69 \%$ as fair; $0-49 \%$ as poor. The comparative evaluation of the results of two procedures of internal fixation in fractures of metacarpals was done. The data was collected systematically and analysed statistically according to paired t-test and chi ${ }^{2}$ test methods.

\section{Results}

The mean age of the patients was 35.2 years. $53.3 \%$ of fracture occurred in age group 31-50 years in group A as compared to $66.7 \%$ of fracture occurred in group B.26.7\% of fracture occurred in age group 15-30 Years in group A as compare to $20 \%$ fracture occurred in group B.20\% of fracture occurred in age group $>50$ years in group A as compared to $13.3 \%$ fracture occurred in group B. Males outnumbered females in sustaining such fractures as they are more involved in outdoor road, industrial and assault activities. Male to female ration is 5:1.Injury was more common in right hand possibly because of the conditioned protective reflex in using the right upper limb more often in a bid to avoid trauma. Also greater than $80 \%$ people are right handed. $60 \%$ of cases was due to road side accident and $40 \%$ was due to assault in group A as compared to $53.3 \%$ of cases was due to road side accident and $40 \%$ was due to assault in group B. There was one case in group B due to railway accident. Present study had $80 \%$ extra articular diaphyseal non comminuted fracture, $20 \%$ diaphyseal comminuted partial articular and $0 \%$ had intra articular fractures along with diaphyseal comminution in group $\mathrm{A}$ as compared to $86.7 \%$ extra articular diaphyseal non comminuted fracture, $13.3 \%$ diaphyseal comminuted partial articular and $0 \%$ had intra articular fractures along with diaphyseal comminution. This study comprised of 30 cases majority of the patient was operated within one week of the surgery with $25(83.3 \%)$ patient having been operated within 3 days of injury \& 4 $(13.3 \%)$ cases having been operated within 4-7 day of injury. One case was operated after one week due to associated abdominal injury.

One patient in group a had fever in comparison to one patient in group B which is not statistical significant $(\mathrm{p}=1.0)$ the fever lasted for two days and subsided with tab. Paracetamol. One patient in group A had discharge from wound in comparison to zero patients in group $B$ which is not statistically significant $(\mathrm{p}=0.309)$ the discharge was purulent due to pyogenic infection. The patient was given antibiotics after culture and sensitivity report for two weeks and daily antiseptic dressings were done. There was complete resolution of discharge following treatment. Two patients in group A had shown post operative stiffness in comparison to four patients in group B which is not statistical significant $(\mathrm{p}=0.361)$ Stiffness was more common in group B as there was restriction of motion due to protruding kirschner's wire around the joint. One patient in group A had shown swelling in comparison to two in group B which is not statistically significant ( $\mathrm{p}=0.543$ ) Zero patients in 
group A and two patients (13.3\%) group B had shown delayed union. one patient in group A had reported tendon rupture in comparison to none in group B. No patient in either group had shown non-union, mal-union or implant failure.

In our study, $100 \%$ rate of union was achieved. In our study 13 patients in group A had shown union in 6-8 weeks; two patients in 9-12 weeks and one patient in $>12$ weeks with average union time of 7.2 week in comparison to 10 patients in group B had shown union in 6-8 weeks; three patients in 912 and two patients in $>12$ weeks with average union time of 9 weeks. The average union time in group A was 7.2 weeks and average union time in group B was 9 weeks. There is no statistical significant difference in the radiological union time between two groups $(\mathrm{p}=0.274)$ and $\left(\mathrm{chi}^{2}\right.$ 2.59).

In our study, nine patients in group A had flexion possible by greater than 59 degree at DIP; five patients had between 49 and 58 degree; one patient had less than 48 degree. This in in comparison to six patients in group B with flexion possible at DIP by more than 59 degree; eight patients between 49 and 58 degree; one patient had less than 48 degree. Five patients in group A had flexion by greater than 93 at PIP joint; eight patients had flexion between 77 and 92 degree; one patient had flexion between 55 and 76 degree and one patients had less than 55 degree. In comparison to four patients in group B had shown flexion possible by greater than 93 degree at IP joint; nine patients had flexion between 77 and 92 degree and one patient had shown flexion between 55 and 76 degree and one patient had flexion less than 55 degree. Seven patients in group A had flexion possible at MCP joint by greater than 76 degree; six patients had flexion between 63 and 75 degree; one patient had flexion between 45 and 62 degree and one patient had flexion less than 45 degree in comparison to six patients in group B had shown flexion possible at MCP joint by greater than 76 degree; six patients had flexion between 63 and 75 degree and two patients had shown flexion between 45 and 62 degree and one had flexion less than 45 degree. Evaluation of result was done according to Strickland's criteria. (Table 1)

Showing Grading of Results according to Strickland's Classification

\begin{tabular}{|l|c|c|c|c|}
\hline \multirow{2}{*}{ Grade } & \multicolumn{4}{|c|}{ Group } \\
\cline { 2 - 5 } & \multicolumn{2}{|c|}{ Group A } & \multicolumn{2}{c|}{ Group B } \\
\cline { 2 - 5 } & No. & $\%$ & No. & $\%$ \\
\hline Excellent & 7 & 46.7 & 6 & 40 \\
\hline Good & 6 & 40 & 6 & 40 \\
\hline Fair & 1 & 6.7 & 2 & 13.3 \\
\hline Poor & 1 & 6.7 & 1 & 6.7 \\
\hline Total & 15 & 100.0 & 15 & 100.0 \\
\hline
\end{tabular}

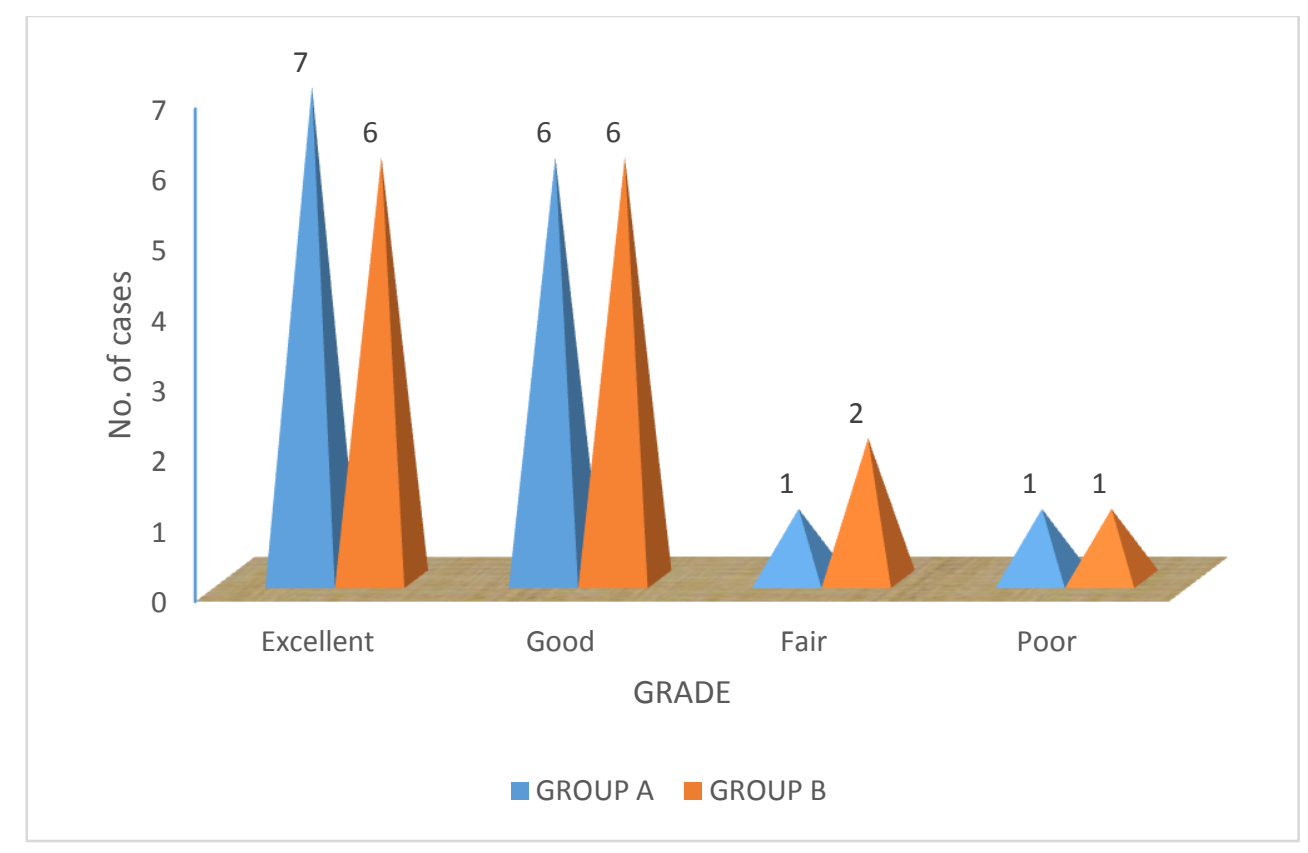




\section{K Wire Cases}

Case 1

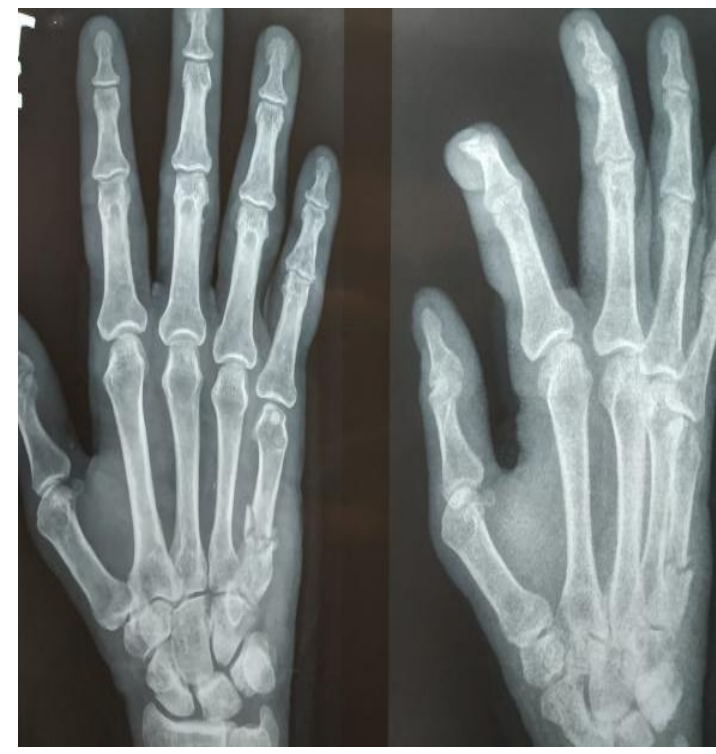

Pre Operative X-Ray

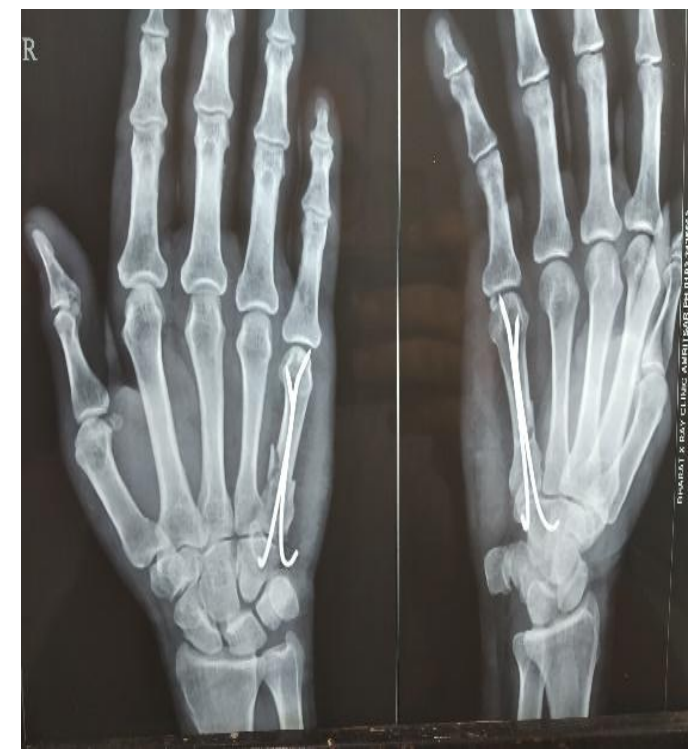

Post Operative X-Ray

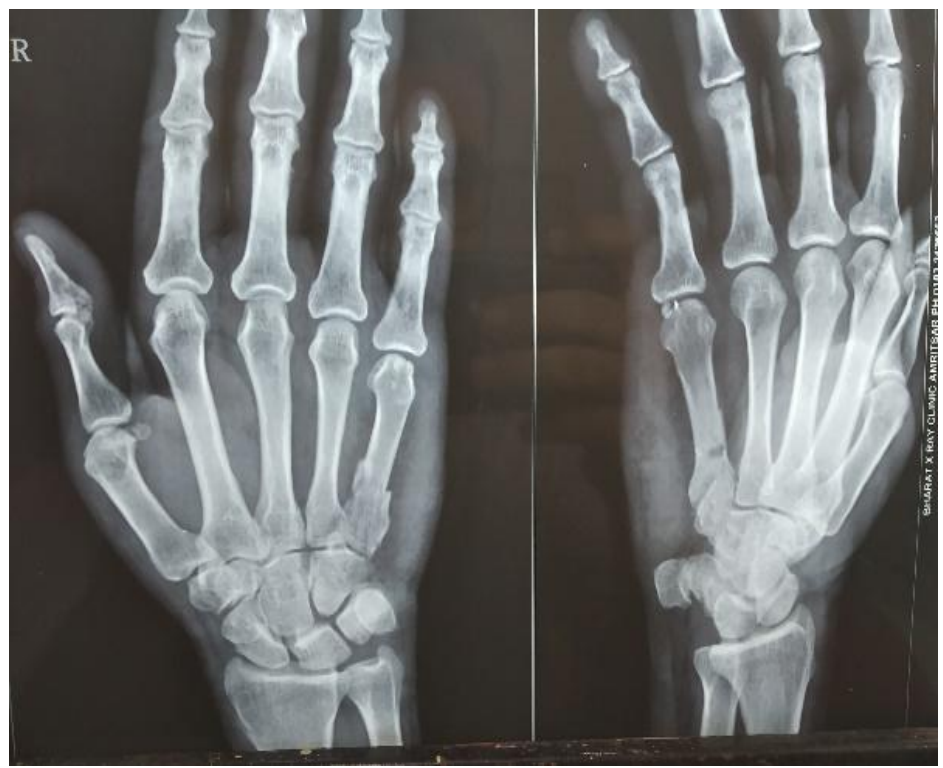

X-Ray Showing Union at 8 Weeks

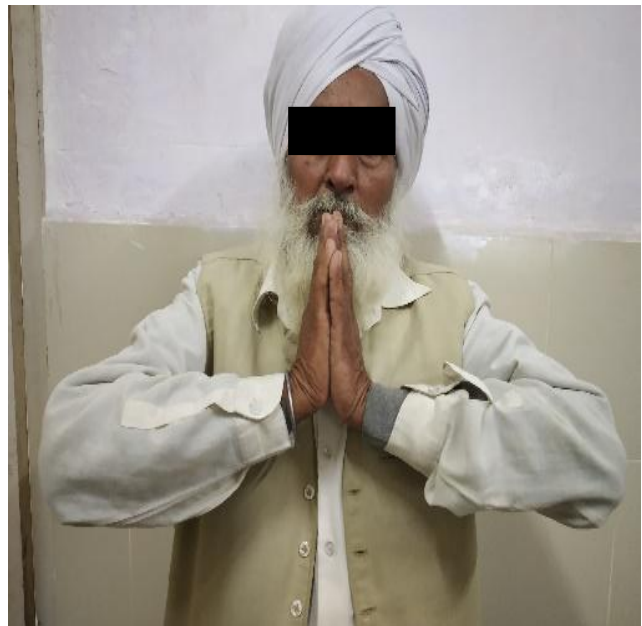

Dorsiflexion at Carpometa Carpal Joint

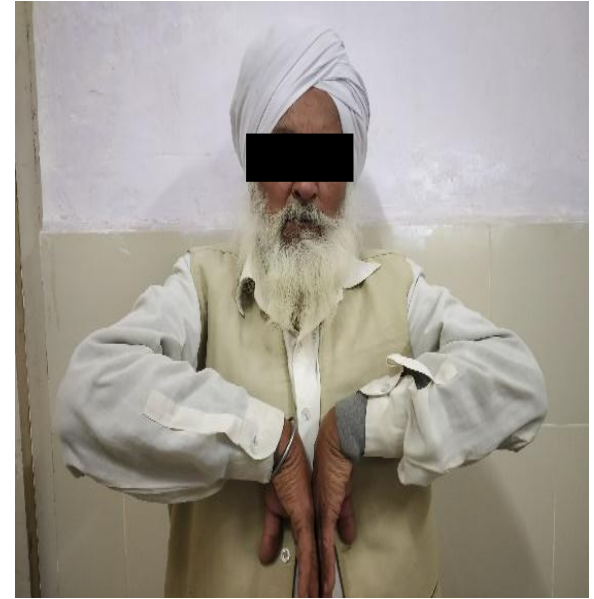

Palmar Flexion at Carpometa Carpal Joint 


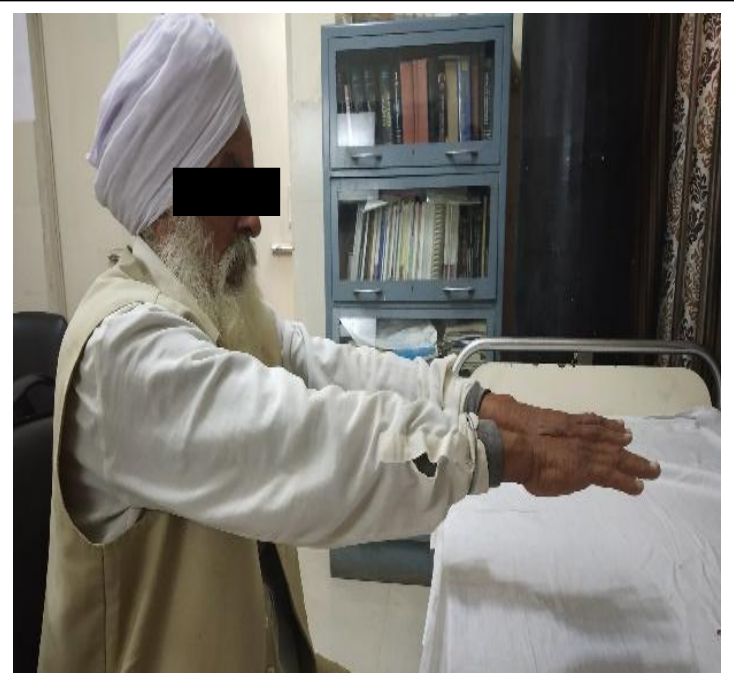

Extension At Mcp Joint, Pip Joint and Dip Joint

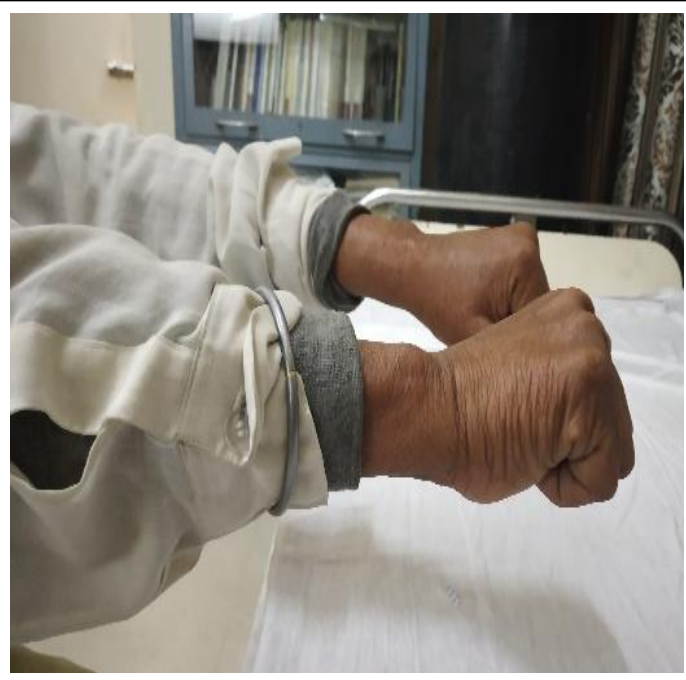

Flexion at Mcp, Pip and Dip Joint

Minifracment Plate Cases

Case 1

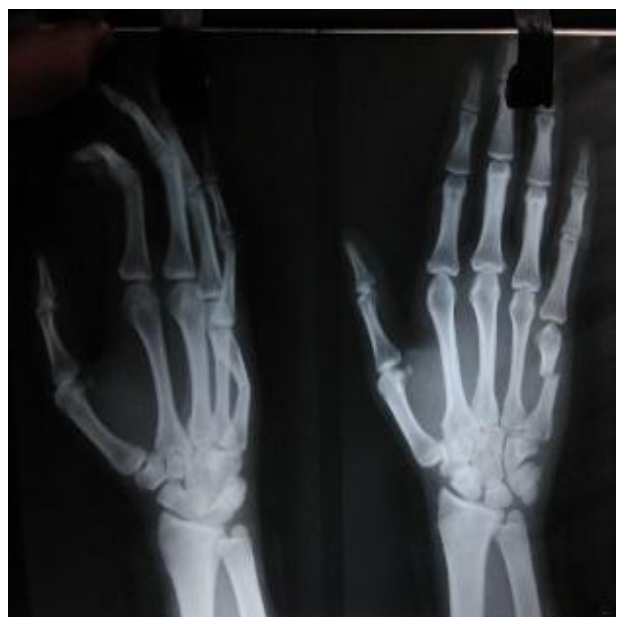

Pre Operative X-Ray

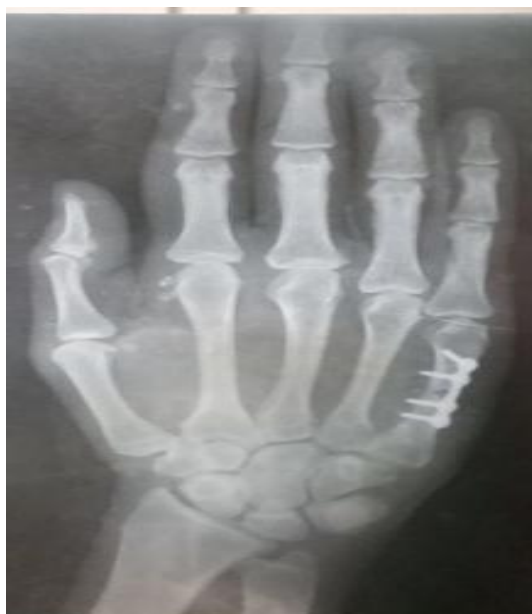

Post Operative X-Ray

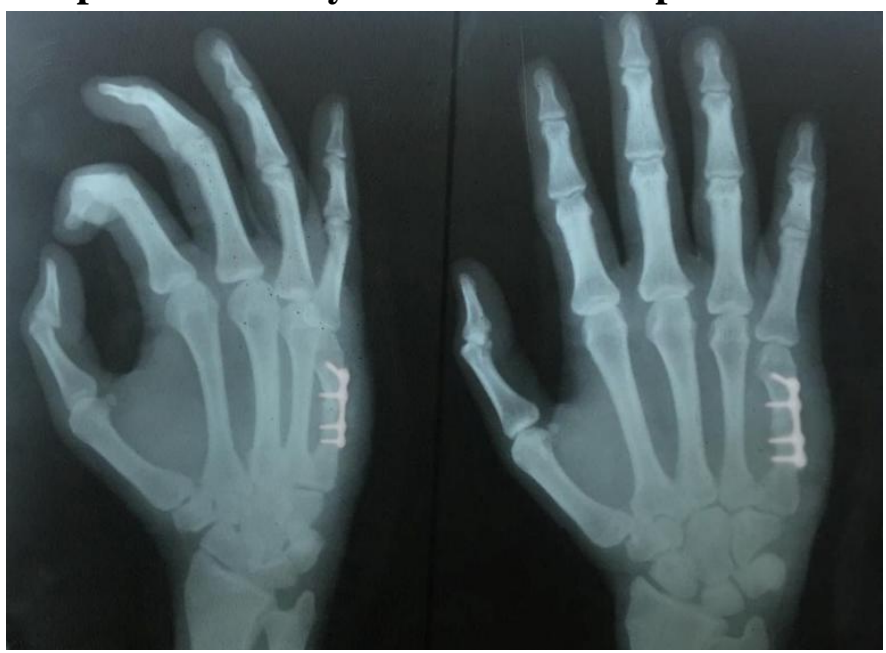

X-Ray Showing Union at 8 Weeks 


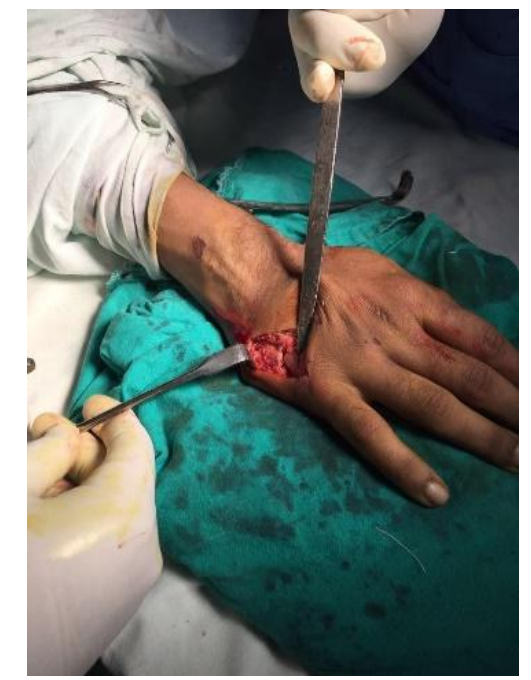

Intra Operative Showing Fracture

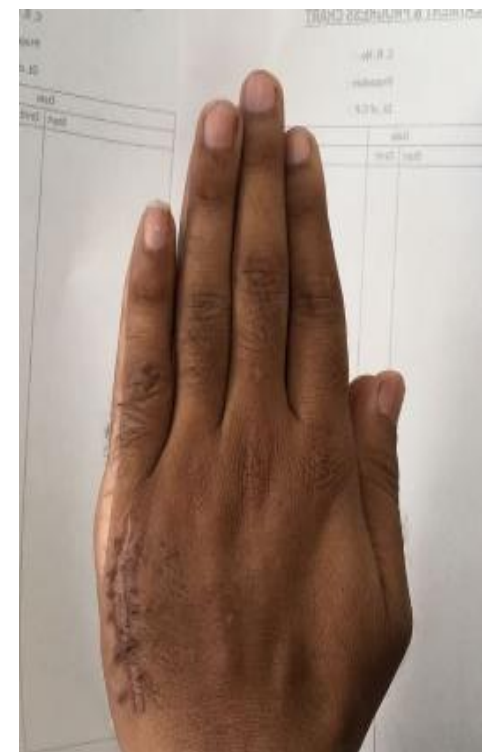

Dorsiflexion at Carpometa Carpal Joint

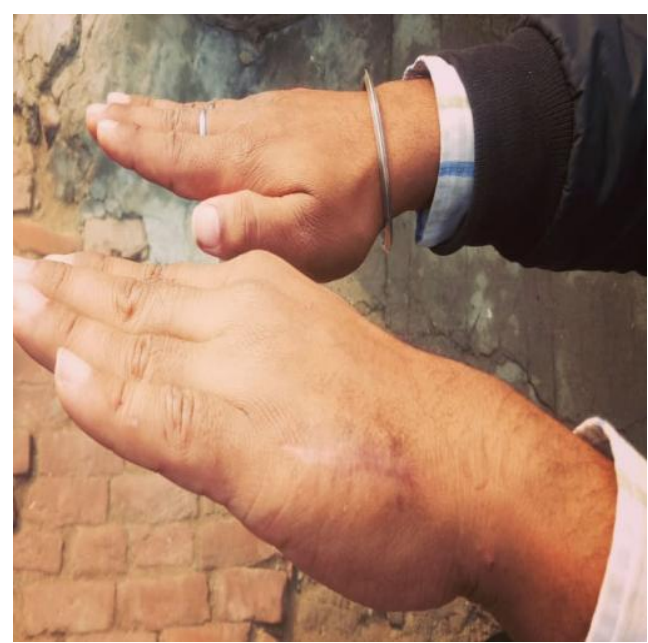

Extension at MCP Joint, Pip Joint and Dip Joint

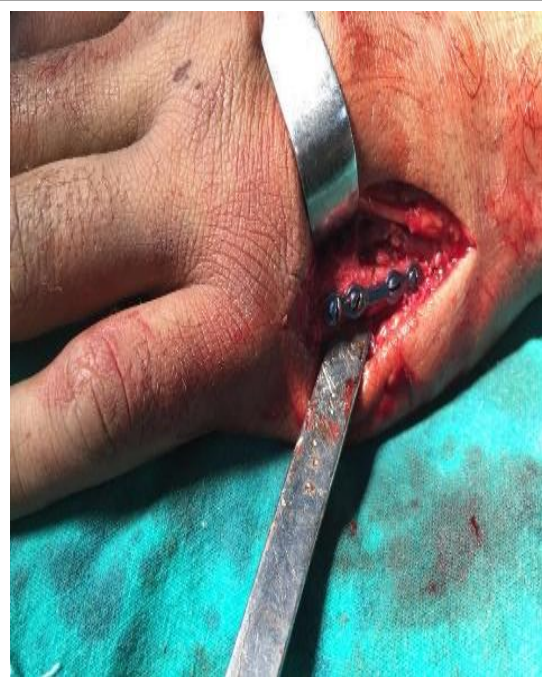

Intra Operative Showing Fracture Fixation

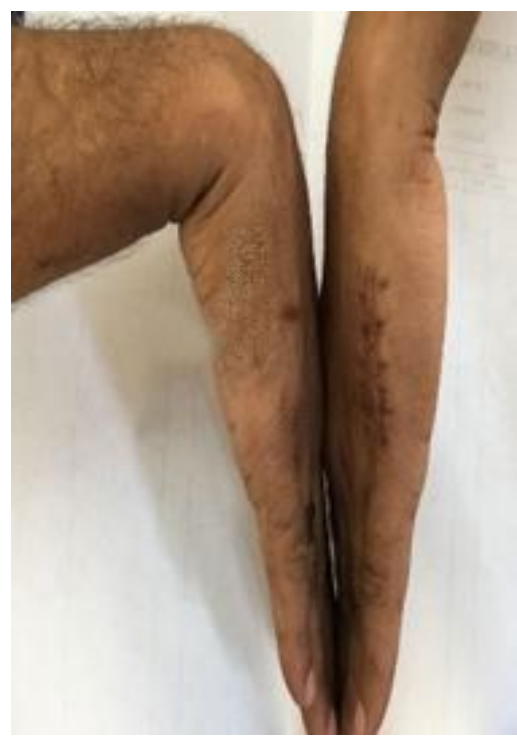

Palmar Flexion at Carpometa Carpal Joint

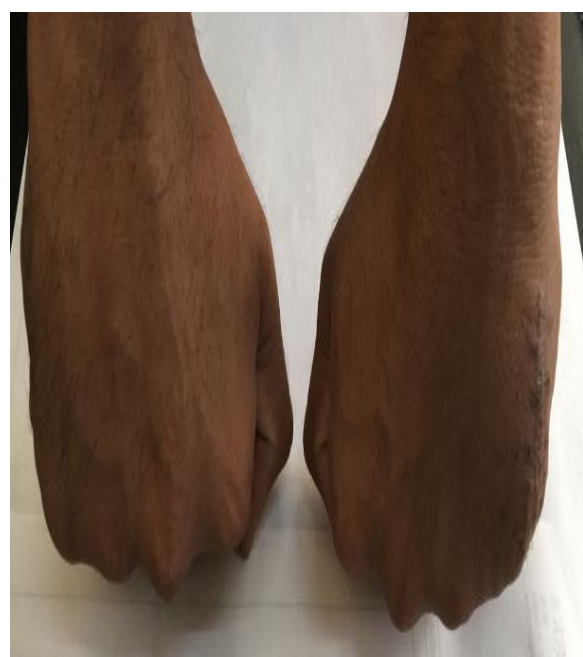

Flexion at MCP, Pip and Dip Joint 


\section{Discussion \& Conclusion}

Most of the metacarpal fractures are stable before or after closed reduction and are managed successfully by conservative method of protective splinting followed by early mobilization. ${ }^{6,7}$ Only a small percentage of metacarpal fractures are unstable and in these patients the functional results following closed treatment are unsatisfactory. These are the cases indicated for open reduction and internal fixation which are usually less than $5 \%$ of hand fractures. ${ }^{8}$ James et al reported that closed method used in treatment of unstable fractures had loss of function in $77 \%$ of fingers. ${ }^{9}$ In our study, $100 \%$ rate of union was achieved. In our study 13 patients in group A had shown union in 6-8 weeks; two patients in 9-12 weeks and one patient in $>12$ weeks with average union time of 7.2 week in comparison to 10 patients in group B had shown union in 6-8 weeks; three patients in 9-12 and two patients in $>12$ weeks with average union time of 9 weeks. The average union time in group A was 7.2 weeks and average union time in group B was 9 weeks. There is no statistical significant difference in the radiological union time between two groups $(\mathrm{p}=0.274)$ and $\left(\mathrm{chi}^{2} 2.59\right)$. Liew $\mathrm{KH}$ et $\mathrm{al}^{10}$ noted $100 \%$ union with the use of kirschner's wire in treatment of fracture of hand in 5.7 weeks. Omakawa et $\mathrm{al}^{33}$ and Nabantoglu et $\mathrm{al}^{34}$ reported union rate of $100 \%$ in fractures of hand treated with minifragment plating. Omakawa et $\mathrm{al}^{11}$ achieved union in 10 weeks.In our study seven patients (46.7) in group A had shown excellent results in comparison to six patients $(40 \%)$ in group B; six patients (40\%) in group A had shown good results in comparison to six patients (40\%) in group B; one patients (6.7) in group A had shown fair result in comparison to two patients $(13.3 \%)$ in group B and one patients (6.7\%) in group A had shown poor result in comparison to one patient $(6.7 \%)$ in group B. The poor result was due to associated infection and swelling which lead to stiffness and marked decrease in range of motion. There is a no statistical significant difference $(\mathrm{p}=0.938)\left(\mathrm{chi}^{2}\right.$ 0.410) in two groups in their results. It was concluded plate fixation is a good option for treating closed unstable metacarpal fractures, where other modalities of fixation are less effective due to the rigid stable fixation provided by plating which withstands load without failure and allowed early mobilization which achieved good functional results. Thus, we conclude that there is a trend towards the use of miniplates over Kirschner's wire in the treatment of fractures of hand. Both Kirschner's wire and miniplating were good methods of internal fixation in fractures of metacarpal; though patients who were treated with miniplating had marginally better results, but the difference was not statistically significant.

\section{References}

1. Swanson AB. Fractures involving the digits of the hand. Orthop Clin North Am. 1970;1:261.

2. Packer GJ, Shaheen MA. Patterns of hand fractures and dislocations in a district general hospital. J Hand Surg (Br) 1993;18:511-4.

3. Gudmundsen TE, Borgen L. Fractures of the fifth metacarpal. Acta Radiol 2009;50:296-300.

4. Brenwald J. Bone healing in the hand. ClinOrthopRelat Res. 1987;214:7-10.

5. Ozer K, Gillani S, Williams. Comparison of intramedullary nailing versus platescrew fixation of extra-articular metacarpal fractures. J Hand Surg Am. 2018;33(10):1724-31.

6. Barton N. Conservative treatment of articular fractures in the hand. J Hand Surg Am. 1989;14:386-90.

7. Wright TA. Early mobilization in fractures of the metacarpals and phalanges. Can $\mathbf{J}$ Surg. 1968;11:491-8.

8. Amadio PC. Fractures of the hand and the wrist. In: Jupiter JB (ed) Flynn's hand surgery. Williams \& Wilkins, Baltimore. 1991; pp 122-85. 
9. James JIP. Fractures of the proximal and middle phalanges of the fingers. ActaOrthop Scand. 1962;32:401-12.

10. Liew KH, Chan BK, Low CO. Metacarpal and proximal phalangeal fractures fixation with multiple intramedullary Kirschner wires. Hand Surg. 2000;5(2):125-30.

11. Omokawa S, Fujitani R, Dohi Y, Okawa T, Yajima H. Prospective outcomes of comminuted periarticular metacarpal and phalangeal fractures treated using a titanium plate system. The Journal of hand surgery. 2008;33(6):857-63. 